\title{
Current Trends in the Management of Gastroesophageal Reflux Disease: A Review
}

\author{
Sylvester Chuks Nwokediuko \\ Gastroenterology Unit, Department of Medicine, University of Nigeria Teaching Hospital Ituku/Ozalla, PMB, \\ Enugu 01129, Nigeria \\ Correspondence should be addressed to Sylvester Chuks Nwokediuko, scnwokediuko@yahoo.com
}

Received 28 April 2012; Accepted 28 May 2012

Academic Editors: P. Correa and C.-T. Shun

Copyright (C 2012 Sylvester Chuks Nwokediuko. This is an open access article distributed under the Creative Commons Attribution License, which permits unrestricted use, distribution, and reproduction in any medium, provided the original work is properly cited.

\begin{abstract}
Gastroesophageal reflux disease (GERD) is a chronic disorder of the upper gastrointestinal tract with global distribution. The incidence is on the increase in different parts of the world. In the last 30 to 40 years, research findings have given rise to a more robust understanding of its pathophysiology, clinical presentation, and management. The current definition of GERD (The Montreal definition, 2006) is not only symptom-based and patient-driven, but also encompasses esophageal and extraesophageal manifestations of the disease. The implication is that the disease can be confidently diagnosed based on symptoms alone. Nonerosive reflux disease (NERD) remains the predominant form of GERD. Current thinking is that NERD and erosive reflux disease (ERD) are distinct phenotypes of GERD rather than the old concept which regarded them as components of a disease spectrum. Non erosive reflux disease is a very heterogeneous group with significant overlap with other functional gastrointestinal disorders. There is no gold standard for the diagnosis of GERD. Esophageal pH monitoring and intraluminal impedance monitoring have thrown some light on the heterogeneity of NERD. A substantial proportion of GERD patients continue to have symptoms despite optimal PPI therapy, and this has necessitated research into the development of new drugs. Several safety concerns have been raised about chronic use of proton pump inhibitors but these are yet to be substantiated in controlled studies. The debate about efficacy of long-term medical treatment compared to surgery continues, however, recent data indicate that modern surgical techniques and long-term PPI therapy have comparable efficacy. These and other issues are subjects of further research.
\end{abstract}

\section{Introduction}

Gastroesophageal reflux disease (GERD) is a common chronic disorder prevalent in many countries [1]. Apart from the economic burden of the disease and its associated impact on quality of life [2-5], it is the most common predisposing factor for adenocarcinoma of the esophagus. As a conse-quence of the irritation caused by the reflux of acid and bile, adenocarcinoma may develop in these patients, representing the last of a sequence that starts with the development of GERD and progresses to metaplasia (Barrett's esophagus), lowgrade dysplasia, high-grade dysplasia, and adenocarcinoma. Although there has been a decrease in the incidence of squamous cell cancers, the rate of esophageal adenocarcinoma has increased rapidly, and this has been traced to the advent of obesity epidemic, GERD and Barrett's esophagus [6, 7].
Over the years, several issues have emerged regarding the definition, classification, natural history and treatment of GERD, and complications associated with its treatment. This paper focuses on some of these evolving issues. Recent studies, limited to English language, were identified via PubMed searches (1990-2011) with the search terms GERD, NERD, prevalence, incidence, epidemiology, and management. Recent reviews on epidemiology and management were also examined for appropriate references.

\section{Definition}

Until recently, there were many definitions of GERD. The lack of a gold standard for diagnosis made it difficult to adopt a satisfactory definition. The first ever global consensus 
definition was published in 2006. According to that document, GERD is defined as "a condition which develops when the reflux of stomach contents causes troublesome symptoms and/or complications" [1]. Based on this definition, GERD can be classified into 2 syndromes: esophageal and extraesophageal syndromes (Table 1). This definition recognizes that GERD can be diagnosed in primary care on the basis of symptoms alone without additional diagnostic testing. This approach is appropriate for most patients and does not use unnecessary resources. Symptoms reach a threshold where they constitute disease when they are troublesome to patients and affect their functioning during usual activities of living. This patient-centered approach to diagnosis includes asking patients how their symptoms affect their everyday lives.

Heartburn and regurgitation are the characteristic symptoms of GERD. Heartburn is defined as a burning sensation in the retrosternal area. Regurgitation is defined as the perception of flow of refluxed gastric contents into the mouth or hypopharynx. These symptoms are sufficiently descriptive to be diagnostic. Esophageal and extraesophageal symptoms and syndromes that form part of the framework of GERD also include chest pain, sleep disturbances, cough, hoarseness, asthma, and dental erosions (Table 1) [1].

\section{Epidemiology}

Gastroesophageal reflux disease is now the most common upper gastrointestinal disease in the western countries, with $10 \%$ to $20 \%$ of the population experiencing weekly symptoms $[4,8]$. In Asia, the prevalence has been variously reported but is generally lower $(2.3 \%$ by Wong et al. and $6.2 \%$ by Chen et al.) $[9,10]$. Population-based survey studies indicate that the prevalence is rising [5]. Possible explanations for this include aging population, the obesity epidemic (and associated changes in diet or physical activity), and changes in sleep pattern [11].

A limited number of studies have reported GERD and its complications to be rare in Africa [12]. However, a recent study of Nigerian medical students showed a prevalence of $26.3 \%$ [13]. Nonerosive reflux disease (NERD) accounts for over $60 \%$ of cases of GERD in Nigeria [14].

\section{Classification}

Gastroesophageal reflux disease is broadly classified into 2 groups on the basis of endoscopy findings: having esophageal mucosal damage (erosive esophagitis and Barrett's esophagus) and no mucosal damage (endoscopy-negative reflux disease or nonerosive reflux disease, NERD).

Traditionally, GERD had been approached as a spectrum disease, with NERD at the mild end and complicated GERD (stricture, Barrett's esophagus, or adenocarcinoma) at the other end of the spectrum. However, emerging evidence indicates that the vast majority of NERD and erosive esophagitis (ER) patients remain within their respective GERD groups throughout their lifetime $[15,16]$. This new paradigm proposes that the genetic makeup of each individual subject exposed to similar environmental factors may ultimately
TABLE 1: The Montreal definition of GERD and its constituent syndromes [1].

\begin{tabular}{l}
\hline Esophageal syndromes \\
\hline Syndromes with symptoms \\
(i) Typical reflux syndrome \\
(ii) Reflux chest pain \\
Syndromes with esophageal injury \\
(i) Reflux esophagitis \\
(ii) Reflux stricture \\
(iii) Barrett's esophagus \\
(iv) Esophageal adenocarcinoma \\
\hline Extraesophageal syndromes \\
\hline Established associations \\
(i) Reflux cough syndrome \\
(ii) Reflux laryngitis syndrome \\
(iii) Reflux asthma syndrome \\
(iv) Reflux dental erosion syndrome \\
Proposed associations \\
(i) Pharyngitis \\
(ii) Sinusitis \\
(iii) Idiopathic pulmonary fibrosis \\
(iv) Recurrent otitis media
\end{tabular}

determine the specific phenotypic presentation of GERD. In other words, GERD phenotypes once determined remain true to form $[15,16]$.

Nonerosive reflux disease (NERD) patients have been subclassified into 3 types on the basis of the results of 24hour $\mathrm{pH}$ evaluation:

Type 1: Patients who demonstrate an abnormal acid exposure time in a manner similar to those with erosive esophagitis [17].

Type 2: Patients with a normal acid exposure time, but with symptoms and reflux events that are significantly correlated, suggesting acid hypersensitivity. This is also referred to as "the hypersensitive esophagus" [17-19].

Type 3: Patients with typical reflux symptoms, but normal $\mathrm{pH}$ studies, and no correlation between symptoms and acid exposure. Within this group are 2 subgroups; namely: those who respond to proton pump inhibitor therapy and those who do not respond. The latter subgroup represents functional heartburn (according to Rome III guideline) [20].

A combination of conventional esophageal $\mathrm{pH}$ monitoring and intraluminal impedance monitoring now offers the opportunity to detect acid and non-acid reflux and their association with symptoms [21]. Using this technique, NERD patients with normal $\mathrm{pH}$ studies were found to have a positive symptom association for acid reflux in $15 \%$ but also a positive association for non-acid reflux in $12 \%$ of patients [22]. These findings have led to the narrowing down of the proportion of patients who were otherwise labeled as presenting with functional heartburn, leading to the identification of a new subgroup of patients whose symptoms are due to reflux other than acid; a subgroup of 
patients with nonacid reflux disease (NARD) or weakly acidic reflux disease (WARD).

\section{Risk Factors}

There is a potential genetic component to the development of GERD and perhaps Barrett's esophagus [23]. In the US, although the frequency of GERD symptoms does not differ between Caucasians and African Americans, the latter group have a persistently lower risk of esophagitis [24]. In a study from Johannesburg, of the 216 consecutive Barrett's esophagus patients only $5 \%$ were black despite the ratio of Blacks to Whites in the city being $5: 1[5]$.

There is evidence to suggest that age and male sex are associated with a higher incidence of esophagitis [25-27]. Obese subjects are 2.5 times more likely to have GERD than those with normal body mass index (BMI) [28]. Several other researchers have reported similar relationship between body mass and GERD [29,30]. Alcohol consumption and the presence of a hiatus hernia are risk factors for GERD and esophagitis $[25,31]$. The presence and size of a hiatal hernia are associated with a more incompetent LES, defective peristalsis, more severe mucosal damage, and increased acid exposure [32]. A Japanese study identified cigarette smoking and alcohol as risk factors for GERD [33]. In Nigeria, increased consumption of cola and coffee by medical students in order to stay awake to read for examinations was associated with an increased prevalence of GERD [14]. One study showed that an initial diagnosis of either GERD or irritable bowel syndrome raised the risk of a subsequent diagnosis of the other three fold [34]. Gastroesophageal reflux disease is frequently found in patients with connective tissue disease, especially scleroderma [35], as well as patients with chronic obstructive airway disease [34]. In addition, a number of common drugs and hormonal products have been associated with GERD. These include anticholinergics, benzodiazepines, calcium channel blockers, dopamine, nicotine, nitrates, theophylline, estrogen, progesterone, glucagon, and some prostaglandins. Heartburn is a very common gastrointestinal manifestation of pregnancy.

\section{Pathophysiology}

Reflux is a normal physiologic occurrence and is produced most often by transient relaxation of the lower esophageal sphincter (LES). In patients with GERD, these transient relaxations occur more frequently than normal. The basal pressure of this sphincter is $10-45 \mathrm{mmHg}$. The crural diaphragm and gastric sling fibres provide structural support and contribute to LES pressure and competence. The ability of the LES to maintain a tone higher than structures proximal and distal is a result of spikes of calcium influx that are mediated by excitatory cholinergic neurons [36]. Higher intracellular calcium levels are present in the resting LES compared with nonsphincteric esophageal muscle. Other defects of the LES that may contribute to GERD include a chronically hypotensive LES and the effects of a hiatal hernia.
Under normal situations, endogenous defense mechanisms either limit the amount of noxious material that is introduced into the esophagus or rapidly clear the material from the esophagus so that symptoms and esophageal mucosal irritation are minimized. Examples of such defense mechanisms include actions of the LES and normal esophageal motility. When the defense mechanisms are defective or become overwhelmed so that the esophagus is bathed in acid or bile-containing fluid for prolonged periods, GERD can be said to exist.

The esophagus, LES, and stomach can be likened to a simple plumbing circuit [37]. The esophagus functions as an anterograde pump, the LES as a valve, and the stomach as a reservoir. The abnormalities that contribute to GERD can stem from any component of the system. A dysfunctional LES allows reflux of large amounts of gastric juice. Delayed gastric emptying can increase volume and pressure in the reservoir until the valve mechanism is overwhelmed, leading to GERD. Esophageal defense mechanisms include esophageal clearance and mucosal resistance. Esophageal clearance has a mechanical arm (esophageal peristalsis) and a chemical component (saliva), both of which limit the amount of time the esophagus is exposed to refluxed gastric juice.

Transient relaxation of the LES can be caused by foods (coffee, alcohol, chocolate, fatty and meals), medications (beta-blockers, nitrates, calcium channel blockers, anticholinergics), hormones (progesterone), and nicotine.

Regarding the effect of hiatal hernia, not all patients with hiatal hernias have symptomatic reflux. In the presence of a hiatal hernia, the LES may migrate proximally into the chest and lose its abdominal high-pressure zone (HPZ), or the length of the HPZ may decrease. The diaphragmatic hiatus may be widened by a large hernia, which impairs the ability of the crura to function as an external sphincter. Also the gastric contents may be trapped in the hernia sac and reflux proximally into the esophagus during relaxation of the LES. Reduction of the hernias and crural closure result in the restoration of an adequate intra-abdominal length of esophagus and recreating the HPZ.

\section{Diagnosis}

There is no gold standard for the diagnosis of GERD. Endoscopy is positive in only about $40 \%$ of cases [14]. Furthermore, the evaluation of antireflux therapies is based on resolution of symptoms and this suffers greatly from subjectivity. The Society of American Gastrointestinal Endoscopic surgeons (SAGES) Practice Guidelines stipulates that the diagnosis of GERD can be confirmed if at least one of the following conditions exists: a mucosal break seen on endoscopy in a patient with typical symptoms, Barrett's esophagus on biopsy, a peptic stricture in the absence of malignancy, or positive $\mathrm{pH}$-metry [38]. This definition obviously excludes patients with NERD who are negative on pH-metry. Therefore, an objective diagnostic tool with acceptable sensitivity and specificity remains an unmet need for clinicians and researchers. 
7.1. Clinical Diagnosis. Heartburn and regurgitation are characteristic symptoms of the typical reflux syndrome [9]. The typical reflux syndrome can be diagnosed on the basis of characteristic symptoms without diagnostic testing [1], provided that alarm symptoms have been excluded. Alarm symptoms are symptoms which raise a strong suspicion of malignant disease or complication. They include vomiting, gastrointestinal bleeding, anemia, abdominal mass, unexplained weight loss, and progressive dysphagia.

Over the years, several symptom-based diagnostic questionnaires have been developed to help primary care physicians in making provisional categorization of patients presenting with upper abdominal complaints and in the selection of patients with reflux symptoms for empirical treatment. The original reflux disease questionnaire developed by Carlsson et al. [39] and a modified version of it [40] have proved to be useful in this respect.

7.2. Radiology. This has a low sensitivity and specificity for the diagnosis of erosive esophagitis. It has no place in the diagnosis of NERD.

7.3. Endoscopy. This has a high specificity but low sensitivity as over $60 \%$ of patients with GERD actually have NERD [14]. In future, new imaging procedures are likely to shed more light on cases that were hitherto classified as NERD by standard white light endoscopy. Such emerging procedures include high-resolution magnification endoscopy, chromoendoscopy, narrow-band imaging, and confocal endomicroscopy [41-43].

7.4. Histology. Various histological lesions have been described in NERD. These include dilated intercellular spaces (DIS) [44], basal cell hyperplasia [45], papilla elongation [46], intraepithelial eosinophils [47], and neutrophils [48], with varying sensitivities and specificities. Zentilin et al. [49] proposed a scoring system that takes multiple possible histologic abnormalities into account. Using a receiver operator characteristic curve analysis, a score of 2 was identified as optimal cut-off value for separating GERD patients from controls. A recent study of Nigerian patients with NERD showed a high degree of intraepithelial neutrophil infiltration of the esophageal mucosa; a finding that may be related to the relative rarity of Barrett's esophagus in Nigerians, and indeed black patients [50]. Despite the diagnostic potential of histology, the widespread use of histopathology in clinical practice is hampered by the need for standardization of biopsy and microscopy techniques.

7.5. Proton Pump Inhibitor (PPI) Test. In this test, a short trial of PPI to determine if the patient is going to have symptom relief is carried out. Significant symptom improvement suggests GERD. False positive and false negative results can occur in this test. If the patient's history is typical for uncomplicated GERD, an initial PPI trial (including lifestyle modification) is appropriate [51]. This is the position of the American Gastroenterological Association. The Asia-Pacific
Consensus on the management of GERD also favors this approach [52].

7.6. Manometry. In patients with persistent reflux symptoms despite PPI therapy and normal findings on endoscopy a further evaluation with manometry is indicated to identify alternative diagnosis, such as motor esophageal abnormalities. Manometry helps to analyze the function and the peristaltic activity of the body of the esophagus and the lower esophageal sphincter (LES) prior to antireflux surgery. However manometry is not indicated for confirming a suspected diagnosis of GERD. It is mainly used to establish the diagnosis of dysphagia in cases in which a mechanical obstruction (e.g., stricture) cannot be found. It is also indicated for the preoperative assessment of candidates for antireflux surgery, to exclude achalasia or ineffective peristalsis [53]. Moreover, manometry serves to localize the LES for subsequent $\mathrm{pH}$ monitoring for documentation of abnormal esophageal acid exposure.

7.7. Ambulatory $p H$ Monitoring. Patients with NERD who do not respond to medications are best evaluated by ambulatory $\mathrm{pH}$ monitoring. The test should be performed-off therapy if the diagnosis is under question but should be performedon therapy if one is trying to determine the adequacy of treatment. The wireless $\mathrm{pH}$ radiotelemetry capsule eliminates the need for the uncomfortable nasogastric tube and increases diagnostic yield by allowing for longer monitoring. Ambulatory esophageal $\mathrm{pH}$ monitoring is based upon the duration of time the intraesophageal $\mathrm{pH}$ is less than 4 , with normal defined as less than $4 \%$ over a 24 -hour period [54]. Up to $50 \%$ of patients with NERD have a normal 24 -hour $\mathrm{pH}$ monitoring study.

Esophageal impedance $\mathrm{pH}$ monitoring is a very promising technique. Multichannel intraluminal impedance monitoring with $\mathrm{pH}$ sensor (MII-pH) can detect all types of reflux (acidic, weakly acidic, and weakly alkaline). This test measures the resistance of electrical conductivity of the esophageal content, thus detecting any change of esophageal $\mathrm{pH}$ due to the presence of liquid or gas reflux $[55,56]$.

\section{Treatment}

The goals of treatment include relief of symptoms, healing of esophagitis, prevention of recurrence, and prevention of complications. The principles of treatment include lifestyle modifications and control of gastric acid secretion using drugs or surgical treatment with corrective antireflux surgery.

8.1. Lifestyle/Dietary Modifications. These are considered the first line of treatment. They include weight loss (for patients who are overweight); avoiding alcohol, chocolate, citrus juice, tomato-based products, peppermint, coffee, and onion. Other measures include avoiding large meals, decreasing fat intake, cessation of smoking, elevation of head of the bed, and avoiding recumbency for 3 hours postprandial [57]. Although there are no randomized trials to test the efficacy of 
these measures, most gastroenterologists are of the opinion that it is reasonable to employ them. Pregnant women who have GERD should be offered lifestyle modification as firstline therapy.

8.2. Antacids/Alginates. These are effective in symptom relief [58-60] and should be taken after each meal and at bed time.

8.3. Acid Suppressive Therapy. Currently, acid suppressive therapy forms the mainstay of GERD treatment [61]. Histamine 2 receptor antagonists (H2RAs) can decrease gastric acid secretion after a meal and are better than antacids [62]. however, they are not efficacious in the healing of esophagitis and maintenance therapy with standard doses of H2RAs cannot prevent relapses [63]. Today they are used for the treatment of milder forms of the disease and for on-demand therapy, especially for nocturnal symptoms [64].

Proton pump inhibitors (PPI) are the most potent type of acid suppressants. They are substituted benzimidazoles that irreversibly bind the $\mathrm{H}^{+} \mathrm{K}^{+}$ATPase, the final step in gastric acid secretion [65]. Several trials and reviews have shown the superiority of PPIs over H2RAs in the treatment of reflux esophagitis [61, 62, 66, 67]. For patients with NERD, resolution of symptoms with PPIs is inferior to the response in erosive esophagitis as only $61 \%$ of patients experience resolution of heartburn, which is still better than $40 \%$ reported for H2RAs $[68,69]$.

Clinical experience shows that $20-30 \%$ of patients with GERD continue to have persistent reflux symptoms even while taking PPI daily [70] and one quarter of patients report the use of additional over-the-counter therapies to aid in symptom control [71]. Putative mechanisms for failure of PPI treatment include compliance, improper dosing time, weakly acidic reflux, duodenogastroesophageal reflux (DGER), delayed gastric emptying, esophageal hypersensitivity, eosinophilic esophagitis, nocturnal reflux, residual acid reflux, reduced PPI bioavailability, and psychological comorbidity [72, 73].

Prokinetic agents are somewhat effective but only in patients with mild symptoms; other patients usually require additional acid-suppressing medications such as PPIs. Metoclopramide is a commonly used member of this group. Domperidone has the advantage of less extrapyramidal effects. Long-term use of prokinetic agents may have serious, even potentially fatal complications and should be discouraged. Randomized controlled trials provide moderatequality evidence that prokinetic drugs improve symptoms in patients with reflux esophagitis and low-quality evidence that they have impact on endoscopic healing [74].

8.4. Maintenance Therapy. Recurrence of esophagitis is substantially reduced in patients who receive daily PPI therapy [61]. Maintenance therapy for GERD is recommended at the lowest effective dose. Evidence from randomized controlled trials demonstrate that subjects treated with an H2RA as maintenance are twice as likely to have recurrent esophagitis as those treated with a PPI. However, among patients with NERD, on-demand regimens may be effective [61].
8.5. Issues with Chronic PPI Therapy. Proton pump inhibitors are generally well tolerated but there are reports of minor side effects such as headache, diarrhea, and abdominal pain $[75,76]$. In general, these occur in about $1-4 \%$ of patients and resolve when the treatment is discontinued. Over the short term, PPIs are safe.

The long-term safety of PPIs is not completely understood. Some safety issues have been raised, although most of these have been in epidemiologic, case-control studies. Epidemiologic data are useful in looking for associations, which of course, should not be confused with causality.

Proton pump inhibitors cause hypergastrinemia in response to acid suppression. Enterochromaffin-like cell (ECL), hyperplasia, and carcinoid tumors have been described in rats [77], raising a safety concern in humans. However, several studies in humans did not show similar lesions [78-81]. The associations of fractures of hip, wrist, forearm, and other sites appear weak and only slightly higher than the risks in control populations matched for age [8285]. However, there is an urgent need for careful prospective studies of the effects of PPIs on bone metabolism and for epidemiological studies carefully designed to minimize confounding by various clinical variables. The risks of Clostridium difficile colitis, other enteric infections, small bowel bacterial overgrowth, and possibly spontaneous bacterial peritonitis also appear increased [86-88]. Impaired gastric secretion may adversely affect the absorption of various nutrients but their clinical impact is still ill-defined [89]. Interaction of PPI with other drugs has assumed tremendous importance recently. Co-therapy with clopidogrel and lowdose PPI therapy is widely used to minimize the risk of serious gastrointestinal bleeding, particularly in high-risk patients, so a balancing of risks in the individual patient is appropriate. Although the FDA has recently promulgated some cautionary statements, these remain controversial [90].

The true importance of these concerns regarding the safety of long-term PPI use can only be estimated from prospective and where possible randomized studies designed solely to measure safety, with minimal confounding.

\section{Newer Treatments}

Acid-suppressive therapy currently forms the mainstay of treatment for GERD, and PPI is the drug of choice in this regard [51]. However, a substantial proportion of patients diagnosed with GERD continue to experience symptoms despite PPI treatment [70, 91], and $22 \%$ of PPI users report taking additional over-the-counter (OTC) medicines to control their symptoms [71].

Transient lower esophageal sphincter relaxation (TLESR) is an important factor behind the occurrence of reflux, and preclinical studies have identified gamma aminobutyric acid (GABA) type $\mathrm{B}$ receptor $\left(\mathrm{GABA}_{\mathrm{B}}\right)$ agonists and metabotropic glutamate receptor 5 (mGluR5) modulators as candidate drugs for modifying TLESR. Baclofen is an example of the former, while ADX10059 is an example of the latter. Both drugs reduce the incidence of TLESR but poor tolerability is the key issue with these drugs [92]. 
TABle 2: Potential advantages and disadvantages of medical therapy and antireflux surgery in the management of chronic gastroesophageal reflux disease [104].

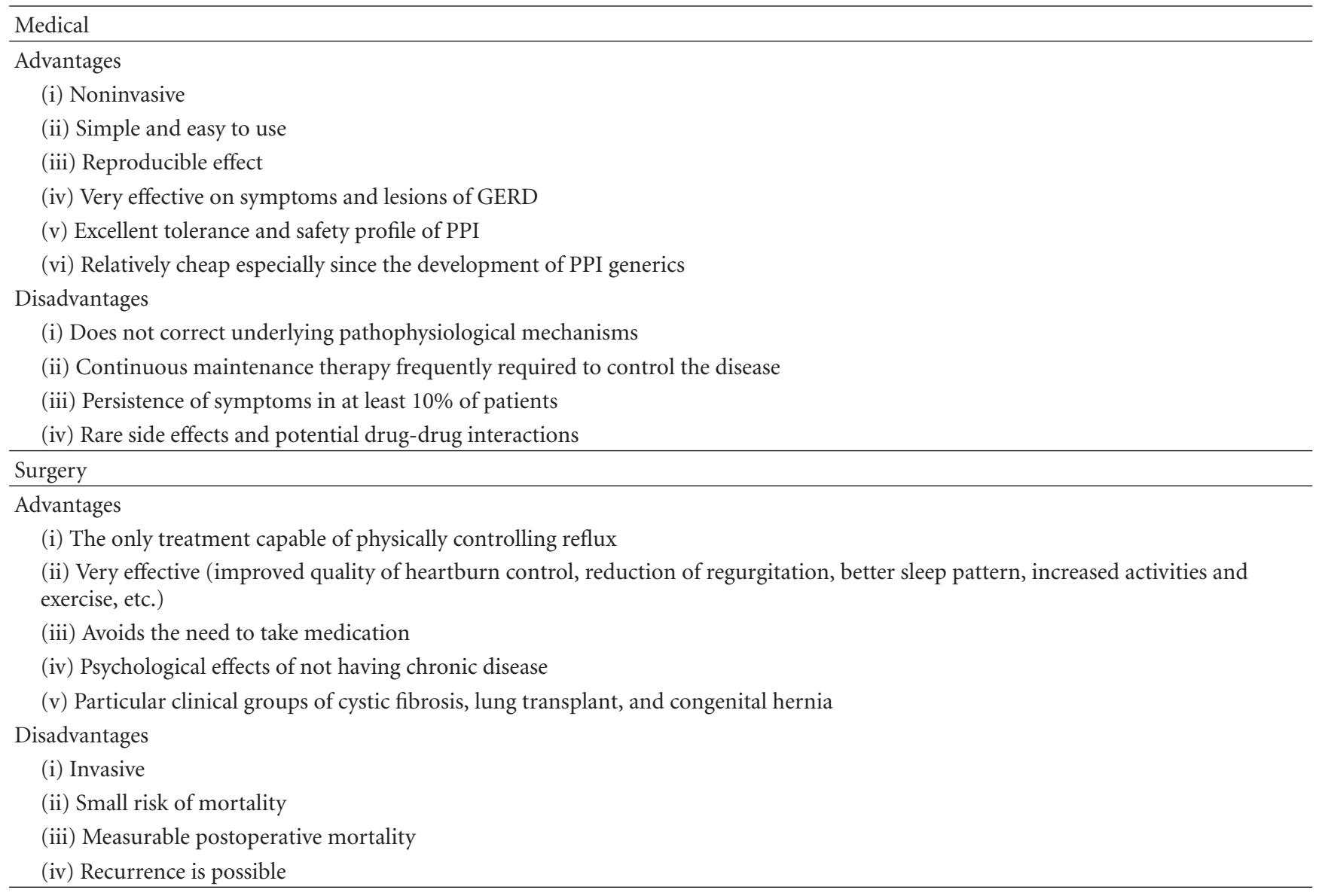

Potassium-competitive acid blockers (P-CAB) are a group of acid-suppressive drugs that inhibit gastric $\mathrm{H}^{+} \mathrm{K}^{+}$ATPase (proton pump) reversibly rather than irreversibly. Whereas the PPIs covalently and irreversibly block the proton pump of the gastric parietal cell [93, 94], P-CABs exert their effect by reversible, potassium-competitive binding at, or near, the potassium-binding site on the proton pump [95]. Unfortunately randomized, double-blind trials have not demonstrated any superiority of P-CABs over PPIs [95, 96]. However, there are two other molecules in the same group that are showing some promise $[97,98]$.

5-hydroxytryptamine type $4\left(5-\mathrm{HT}_{4}\right)$ receptor agonists increase gastric smooth muscle contractility. This receptor is a potential new target in GERD [99]. Drugs in this class include cisapride, monsapride, and togaserod (which is also used in the treatment of constipation and irritable bowel syndrome). However, safety issues have limited their usefulness in contemporary clinical practice [100, 101]. ATI7505 is a cisapride analogue that is currently undergoing trial [102].

Known modulators of visceral pain such as tricyclic antidepressants and selective serotonin reuptake inhibitors (SSRIs) may present an attractive option for GERD patients. A randomized double-blind trial assessing the efficacy of pain modulation with nortriptyline, a tricyclic antidepressant in patients with GERD who have failed to respond to standard-dose PPI therapy is currently on-going [103].

\section{Surgery}

To address the chronic and relapsing nature of GERD, two treatment options are available and these are long-term medication and surgery. The advantages and disadvantages of long-term medical treatment and surgery are shown in Table 2 [104]. A multicentre study which compared optimized esomeprazole therapy and standard laparoscopic antireflux surgery (LARS) in patients with GERD demonstrated that both approaches are equally effective as most patients achieve and remain in remission at 5 years [105].

\subsection{Indications for Surgery}

(1) Failed medical management (inadequate symptom control, severe regurgitation not controlled with acid suppression, or medication side effects).

(2) Patients who opt for surgery despite successful medical management (due to quality of life considerations, 
life-long need for medication intake, expense of medication etc.)

(3) Complications of GERD (Barrett's esophagus, peptic stricture) $[106,107]$.

(4) Extraesophageal manifestations (asthma, hoarseness, cough, chest pain, and aspiration) [108-111]. The coexistence of Barrett's esophagus with reflux symptoms is considered by many as clear indication for antireflux surgery [112].

Over the past 50 years, surgery for GERD has evolved from an open to a laparoscopic procedure and recently to a new incisionless procedure called transoral incisionless fundoplication. The most common procedure is Nissen fundoplication, which can be open or laparoscopic. Fundoplication can involve a complete (360 degrees) or partial (varying degrees) wrap of the LES with a portion of the stomach, thereby increasing the LES pressure. In the era of open antireflux surgery, symptom response rates of 80 $90 \%$ were reported $[113,114]$. Even at that, many patients avoided it because of high morbidity. With the introduction of laparoscopic techniques, there has been an exponential growth in the number of antireflux operations. The advantages include fewer incisional hernias, shorter hospital stay, less pain, quicker return to work, and fewer defective wraps at follow-up endoscopy [115].

Complications of fundoplication include persistent dysphagia, inability to belch and vomit, epigastric fullness, bloating and postprandial pain, temporary swallowing discomfort, and sometimes intense flatus [116]. Inability to belch, epigastric fullness, bloating, and flatus constitute the syndrome of "gas bloat".

Endoluminal fundoplication is a new, modified version of open or laparoscopic fundoplication which accesses the stomach through the mouth, thereby eliminating the need for incisions.

\section{Overlap of GERD with Other Gastrointestinal Disorders}

Patients with NERD have other functional gastrointestinal symptoms, such as functional dyspepsia and irritable bowel syndrome (IBS), with a frequency higher than that observed in most studies of erosive reflux disease [117119]. A common denominator may well be visceral hypersensitivity [120]. The NERD patient group incorporates subgroups which differ significantly in terms of presentation, pathophysiology, and management. Patients with functional heartburn are more likely to have psychopathology, similar to functional dyspepsia patients [121]. Abdominal symptoms appear to be independent predictors of severity of reflux symptoms in NERD patients when compared to control subjects who do not have such symptoms [122]. The significance of this overlap is still a subject of serious research, and it does appear that more revisions await the classification of functional gastrointestinal disorders.

\section{Conclusion}

In conclusion, GERD is one aspect of gastroenterology that has undergone tremendous innovations in the last 30-40 years and is still an area of intensive research. There have been innovations in the definition, classification, diagnosis, clinical course, and management of GERD. Nonerosive reflux disease (NERD) is the variant of GERD that affects over $60 \%$ of patients with GERD and it is not only more heterogeneous than erosive esophagitis but has a different pathophysiology and response to standard medical therapy. Because GERD is a chronic, relapsing disease, patients have to be managed with either long-term medical treatment or surgery after a thorough analysis of the pros and cons of each modality. A number of issues remain unresolved about GERD and it is hoped that the next couple of years would come with more discoveries in this important disease.

\section{References}

[1] N. Vakil, S. V. van Zanten, P. Kahrilas et al., "The Montreal definition and classification of gastroesophageal reflux disease: a global evidence-based consensus," American Journal of Gastroenterology, vol. 101, no. 8, pp. 1900-1943, 2006.

[2] N. J. Shaheen, R. A. Hansen, D. R. Morgan et al., "The burden of gastrointestinal and liver diseases, 2006," American Journal of Gastroenterology, vol. 101, no. 9, pp. 2128-2138, 2006.

[3] P. Wahlqvist, M. C. Reilly, and A. Barkun, "Systematic review: the impact of gastro-oesophageal reflux disease on work productivity," Alimentary Pharmacology and Therapeutics, vol. 24, no. 2, pp. 259-272, 2006.

[4] J. Dent, H. B. El-Serag, M. A. Wallander, and S. Johansson, "Epidemiology of gastro-oesophageal reflux disease: a systematic review," Gut, vol. 54, no. 5, pp. 710-717, 2005.

[5] H. B. El-Serag, "Time trends of gastroesophageal reflux disease: a systematic review," Clinical Gastroenterology and Hepatology, vol. 5, no. 1, pp. 17-26, 2007.

[6] L. S. Engel, W. H. Chow, T. L. Vaughan et al., "Population attributable risks of esophageal and gastric cancers," Journal of the National Cancer Institute, vol. 95, no. 18, pp. 14041413, 2003.

[7] W. J. Blot, "Esophageal cancer trends and risk factors," Seminars in Oncology, vol. 21, no. 4, pp. 403-410, 1994.

[8] V. Stanghellini, "Relationship between upper gastrointestinal symptoms and lifestyle, psychosocial factors and comorbidity in the general population: results from the Domestic/International Gastroenterology Surveillance Study (DIGEST)," Scandinavian Journal of Gastroenterology, Supplement, vol. 231, pp. 29-37, 1999.

[9] W. M. Wong, K. C. Lai, K. F. Lam et al., "Prevalence, clinical spectrum and health care utilization of gastro-oesophageal reflux disease in a Chinese population: a population-based study," Alimentary Pharmacology and Therapeutics, vol. 18, no. 6, pp. 595-604, 2003.

[10] M. Chen, L. Xiong, H. Chen, A. Xu, L. He, and P. Hu, "Prevalence, risk factors and impact of gastroesophageal reflux disease symptoms: a population-based study in South China," Scandinavian Journal of Gastroenterology, vol. 40, no. 7, pp. 759-767, 2005.

[11] J. V. Lewis, "Editorial: gastroesophageal reflux disease and obesity," Southern Medical Journal, vol. 102, no. 10, pp. 995996, 2009. 
[12] I. Segal, "The gastro-oesophageal reflux disease complex in sub-Saharan Africa," European Journal of Cancer Prevention, vol. 10, no. 3, pp. 209-212, 2001.

[13] S. C. Nwokediuko, "Gastroesophageal reflux disease, a population-based study," Gastroenterology Research, vol. 2, pp. 152-156, 2009.

[14] S. C. Nwokediuko, U. Ijoma, O. Obienu, and C. Agunyenwa, "Gastroesophgeal reflux disease: a clinical and endoscopic study of Nigerian patients," The Internet Journal of Gastroenterology, vol. 8, article 2, 2009.

[15] S. J. Sontag, A. Sonnenberg, T. G. Schnell, J. Leya, and A. Metz, "The long-term natural history of gastroesophageal reflux disease," Journal of Clinical Gastroenterology, vol. 40, no. 5, pp. 398-404, 2006.

[16] A. Agrawal and D. Castell, "GERD is chronic but not progressive," Journal of Clinical Gastroenterology, vol. 40, no. 5, pp. 374-375, 2006.

[17] J. Dent, J. Brun, A. M. Fendrick et al., "An evidencebased appraisal of reflux disease management- the Genval Workshop Report," Gut, vol. 44, 2, pp. S1-S16, 1999.

[18] R. Fass, M. B. Fennerty, and N. Vakil, "Non erosive reflux disease-current concepts and dilemmas," American Journal of Gastroenterology, vol. 96, no. 2, pp. 303-314, 2001.

[19] R. G. P. Watson, T. C. K. Tham, B. T. Johnston, and N. I. McDougall, "Double blind cross-over placebo controlled study of omeprazole in the treatment of patients with reflux symptoms and physiological levels of acid reflux-the 'sensitive oesophagus,"' Gut, vol. 40, no. 5, pp. 587-590, 1997.

[20] D. Drossman Rome III, The Functional Gastrointestinal Disorders, Degnon Associates, McLean, Va, USA, 3rd edition, 2006.

[21] P. Zentilin, P. Dulbecco, E. Savarino, E. Giannini, and V. Savarino, "Combined multichannel intraluminal impedance and pH-metry: a novel technique to improve detection of gastro-oesophageal reflux. Literature review," Digestive and Liver Disease, vol. 36, no. 9, pp. 565-569, 2004.

[22] E. Savarino, P. Zentilin, R. Tutuian et al., "The role of nonacid reflux in NERD: lessons learned from impedance$\mathrm{pH}$ monitoring in 150 patients off therapy," American Journal of Gastroenterology, vol. 103, no. 11, pp. 2685-2693, 2008.

[23] H. Nordenstedt and J. Lagergren, "Environmental factors in the etiology of gastroesophageal reflux disease," Expert Review of Gastroenterology and Hepatology, vol. 2, no. 1, pp. 93-103, 2008.

[24] P. Sharma, S. Wani, Y. Romero, D. Johnson, and F. Hamilton, "Racial and geographic issues in gastroesophageal reflux disease," American Journal of Gastroenterology, vol. 103, no. 11, pp. 2669-2680, 2008.

[25] M. S. Rosaida and K. L. Goh, "Gastro-oesophageal reflux disease, reflux oesophagitis and non-erosive reflux disease in a multiracial Asian population: a prospective, endoscopy based study," European Journal of Gastroenterology and Hepatology, vol. 16, no. 5, pp. 495-501, 2004.

[26] K. Hirakawa, K. Adachi, K. Amano et al., "Prevalence of non-ulcer dyspepsia in the Japanese population," Journal of Gastroenterology and Hepatology, vol. 14, no. 11, pp. 10831087, 1999.

[27] S. Rajendra, K. Kutty, and N. Karim, "Ethnic differences in the prevalence of endoscopic esophagitis and Barrett's esophagus: the long and short of it all," Digestive Diseases and Sciences, vol. 49, no. 2, pp. 237-242, 2004.

[28] H. B. El-Serag, D. Y. Graham, J. A. Satia, and L. Rabeneck, "Obesity is an independent risk factor for GERD symptoms and erosive esophagitis," American Journal of Gastroenterology, vol. 100, no. 6, pp. 1243-1250, 2005.
[29] S. Ayazi, P. Crookes, and C. Peyre, "Objective documentation of the link between GERD and obesity," The American Journal of Gastroenterology, vol. 102, pp. 138-139, 2007.

[30] S. Ayazi, J. A. Hagen, L. S. Chan et al., "Obesity and gastroesophageal reflux: quantifying the association between body mass index, esophageal acid exposure, and lower esophageal sphincter status in a large series of patients with reflux symptoms," Journal of Gastrointestinal Surgery, vol. 13, no. 8, pp. 1440-1447, 2009.

[31] N. S. Buttar and G. W. Falk, "Pathogenesis of gastroesophageal reflux and Barrett esophagus," Mayo Clinic Proceedings, vol. 76, no. 2, pp. 226-234, 2001.

[32] M. G. Patti, H. I. Goldberg, M. Arcerito, L. Bortolasi, J. Tong, and L. W. Way, "Hiatal hernia size affects lower esophageal sphincter function, esophageal acid exposure, and the degree of mucosal injury," American Journal of Surgery, vol. 171, no. 1, pp. 182-186, 1996.

[33] Y. Watanabe, Y. Fujiwara, M. Shiba et al., "Cigarette smoking and alcohol consumption associated with gastro-oesophageal reflux disease in Japanese men," Scandinavian Journal of Gastroenterology, vol. 38, no. 8, pp. 807-811, 2003.

[34] A. Ruigómez, M. A. Wallander, S. Johansson, and L. A. G. Rodríguez, "Irritable bowel syndrome and gastroesophageal reflux disease in primary care: is there a link?" Digestive Diseases and Sciences, vol. 54, no. 5, pp. 1079-1086, 2009.

[35] M. G. Patti, W. J. Gasper, P. M. Fisichella, I. Nipomnick, and F. Palazzo, "Gastroesophageal reflux disease and connective tissue disorders: pathophysiology and implications for treatment," Journal of Gastrointestinal Surgery, vol. 12, no. 11, pp. 1900-1906, 2008.

[36] W. J. Dodds, W. J. Hogan, J. F. Helm, and J. Dent, "Pathogenesis of reflux esophagitis," Gastroenterology, vol. 81, no. 2, pp. 376-394, 1981.

[37] H. J. Stein and T. R. DeMeester, "Outpatient physiologic testing and surgical management of foregut motility disorders," Current Problems in Surgery, vol. 29, no. 7, pp. 413-555, 1992.

[38] D. Stefanidis, W. W. Hope, G. P. Kohn, P. R. Reardon, W. S. Richardson, and R. D. Fanelli, "Guidelines for surgical treatment of gastroesophageal reflux disease," Surgical Endoscopy, vol. 24, no. 11, pp. 2647-2669, 2010.

[39] R. Carlsson, J. Dent, E. Bolling-Sternevald et al., "The usefulness of a structured questionnaire in the assessment of symptomatic gastroesophageal reflux disease," Scandinavian Journal of Gastroenterology, vol. 33, no. 10, pp. 1023-1029, 1998.

[40] W. M. Wong, K. F. Lam, K. C. Lai et al., "A validated symptoms questionnaire (Chinese GERDQ) for the diagnosis of gastro-oesophageal reflux disease in the Chinese population," Alimentary Pharmacology and Therapeutics, vol. 17, no. 11, pp. 1407-1413, 2003.

[41] I. Yoshikawa, M. Yamasaki, T. Yamasaki, K. Kume, and M. Otsuki, "Lugol chromoendoscopy as a diagnostic tool in so-called endoscopy-negative GERD," Gastrointestinal Endoscopy, vol. 62, no. 5, pp. 698-703, 2005.

[42] P. Sharma, S. Wani, A. Bansal et al., "A feasibility trial of narrow band imaging endoscopy in patients with gastroesophageal reflux disease," Gastroenterology, vol. 133, no. 2, pp. 454-464, 2007.

[43] R. Kiesslich, K. Lammersdorf, M. Goetz et al., "Microscopic changes in non-erosive reflux disease can be diagnosed during on-going endomicroscop," Gastrointestinal Endoscopy, vol. 65, Article ID AB243, 2006.

[44] F. Ismail-Beigi, P. F. Horton, and C. E. Pope 2nd. C.E., "Histological consequences of gastroesophageal reflux in man," Gastroenterology, vol. 58, no. 2, pp. 163-174, 1970. 
[45] L. F. Brown, H. Goldman, and D. A. Antonioli, "Intraepithelial eosinophils in endoscopic biopsies of adults with reflux esophagitis," American Journal of Surgical Pathology, vol. 8, no. 12, pp. 899-905, 1984.

[46] C. M. Ballem, H. W. Fletcher, and R. D. Mc Kenna, "The diagnosis of esophagitis," The American Journal of Digestive Diseases, vol. 5, no. 2, pp. 88-93, 1960.

[47] T. E. Knuff, S. B. Benjamin, G. F. Worsham, J. E. Hancock, and D. O. Castell, "Histologic evaluation of chronic gastroesophageal reflux. An evaluation of biopsy methods and diagnostic criteria," Digestive Diseases and Sciences, vol. 29, no. 3, pp. 194-201, 1984.

[48] S. Nandurkar, N. J. Talley, C. J. Martin, and S. Adams, "Esophageal histology does not provide additional useful information over clinical assessment in identifying reflux patients presenting for esophagogastroduodenoscopy," Digestive Diseases and Sciences, vol. 45, no. 2, pp. 217-224, 2000.

[49] P. Zentilin, V. Savarino, L. Mastracci et al., "Reassessment of the diagnostic value of histology in patients with GERD, using multiple biopsy sites and an appropriate control group," American Journal of Gastroenterology, vol. 100, no. 10, pp. 2299-2306, 2005.

[50] S. C. Nwokediuko, U. Ijoma, and O. Okafor, "Esophageal intraepithelial neutrophil infiltration is common in Nigerian patients with non-erosive reflux disease," Gastroenterology Research, vol. 4, no. 1, pp. 20-25, 2011.

[51] K. R. De Vault and D. O. Castell, "Updated guidelines for the diagnosis and treatment of gastroesophageal reflux disease," American Journal of Gastroenterology, vol. 100, no. 1, pp. 190 200, 2005.

[52] K. M. Fock, N. J. Talley, R. Fass et al., "Asia-Pacific consensus on the management of gastroesophageal reflux disease: update," Journal of Gastroenterology and Hepatology, vol. 23, no. 1, pp. 8-22, 2008.

[53] J. P. Waring, J. G. Hunter, M. Oddsdottir, J. Wo, and E. Katz, "The preoperative evaluation of patients considered for laparoscopic antireflux surgery," American Journal of Gastroenterology, vol. 90, no. 1, pp. 35-38, 1995.

[54] P. J. Kahrilas, N. J. Shaheen, and M. F. Vaezi, "American gastroenterological association medical position statement on the management of gastroesophageal reflux disease," Gastroenterology, vol. 135, no. 4, pp. 1383.e5-1391.e5, 2008.

[55] D. Pohl and R. Tutuian, "Reflux monitoring: pH-metry, bilitec and oesophageal impedance measurements," Best Practice and Research, vol. 23, no. 3, pp. 299-311, 2009.

[56] A. Agrawal and D. O. Castell, "Clinical importance of impedance measurements," Journal of Clinical Gastroenterology, vol. 42 , no. 5 , pp. 579-583, 2008.

[57] R. F. Harvey, N. Hadley, T. R. Gill et al., "Effects of sleeping with the bed-head raised and of ranitidine in patients with severe peptic oesophagitis," The Lancet, vol. 2, no. 8569, pp. 1200-1203, 1987.

[58] D. Y. Graham and D. J. Patterson, "Double-blind comparison of liquid antacid and placebo in the treatment of symptomatic reflux esophagitis," Digestive Diseases and Sciences, vol. 28, no. 6, pp. 559-563, 1983.

[59] D. A. Lieberman, "Medical therapy for chronic reflux esophagitis. Long-term follow-up," Archives of Internal Medicine, vol. 147, no. 10, pp. 1717-1720, 1987.

[60] T. Poynbard, "Relapse rate of patients after healing of oesophagitis-a prospective study of alginate as self-care treatment for 6 months," Alimentary Pharmacology and Therapeutics, vol. 7, no. 4, pp. 385-392, 1993.
[61] S. Bruley des Varannes, E. Coron, and J. P. Galmiche, "Short and long-term PPI treatment for GERD. Do we need morepotent anti-secretory drugs?" Best Practice and Research, vol. 24, no. 6, pp. 905-921, 2010.

[62] K. R. De Vault and D. O. Castell, "Updated guidelines for the diagnosis and treatment of gastroesophageal reflux disease," The American Journal of Gastroenterology, vol. 94, no. 6, pp. 1434-1442, 1999.

[63] D. G. Colin-Jones, "The role and limitation of H2-receptor antagonists in the treatment of gastroesophgeal reflux disease," Alimentary Pharmacology \& Therapeutics, vol. 9, pp. 9-14, 1995.

[64] R. Tutuian and D. O. Castell, "Management of gastroesophageal reflux disease," American Journal of the Medical Sciences, vol. 326, no. 5, pp. 309-318, 2003.

[65] P. Richardson, C. J. Hawkey, and W. A. Stack, "Proton pump inhibitors. Pharmacology and rationale for use in gastrointestinal disorders," Drugs, vol. 56, no. 3, pp. 307-335, 1998.

[66] E. C. Klinkenberg-Knol, F. Nelis, J. Dent et al., "Long-term omeprazole treatment in resistant gastroesophageal reflux disease: efficacy, safety, and influence on gastric mucosa," Gastroenterology, vol. 118, no. 4, pp. 661-669, 2000.

[67] M. Khan, J. Santana, C. Donnellan, C. Preston, and P. Moayyedi, "Medical treatments in the short term management of reflux oesophagitis," Cochrane Database of Systematic Reviews, no. 2, Article ID CD003244, 2007.

[68] T. L. Venables, R. D. Newland, A. C. Patel, J. Hole, C. Wilcock, and M. L. Turbitt, "Omeprazole 10 milligrams once daily, omeprazole 20 milligrams once daily, or ranitidine 150 milligrams twice daily, evaluated as initial therapy for the relief of symptoms of gastro-oesophageal reflux disease in general practice," Scandinavian Journal of Gastroenterology, vol. 32, no. 10, pp. 965-973, 1997.

[69] B. Van Pinxteren, M. E. Numans, P. A. Bonis, and J. Lau, "Short-term treatment with proton pump inhibitors, H2receptor antagonists and prokinetics for gastro-oesophageal reflux disease-like symptoms and endoscopy negative reflux disease," Cochrane Database of Systematic Reviews, vol. 3, Article ID CD002095, 2006.

[70] R. Fass, "Proton-pump inhibitor therapy in patients with gastro-oesophageal reflux disease: putative mechanisms of failure," Drugs, vol. 67, no. 11, pp. 1521-1530, 2007.

[71] R. Jones, D. Armstrong, P. Malfertheiner, and P. Ducrotté, "Does the treatment of gastroesophageal reflux disease (GERD) meet patients' needs? A survey-based study," Current Medical Research and Opinion, vol. 22, no. 4, pp. 657-662, 2006.

[72] R. Fass and D. Sifrim, "Management of heartburn not responding to proton pump inhibitors," Gut, vol. 58, no. 2, pp. 295-309, 2009.

[73] J. E. Richter, "The patient with refractory gastroesophageal reflux disease," Diseases of the Esophagus, vol. 19, no. 6, pp. 443-447, 2006.

[74] M. E. Manzotti, H. N. Catalano, F. A. Serrano, G. D. Stilio, M. F. Koch, and G. Guyatt, "Prokinetic drug utility in the treatment of gastroesophgeal reflux esophatitis: a systematic review of randomized controlled trial," Open Medicine, vol. 1, no. 3, 2007.

[75] S. Bruley des Varannes, E. Coron, and J. P. Galmiche, "Short and long-term PPI treatment for GERD. Do we need morepotent anti-secretory drugs?" Best Practice and Research, vol. 24, no. 6, pp. 905-921, 2010. 
[76] F. Lodato, F. Azzaroli, L. Turco et al., "Adverse effects of proton pump inhibitors," Best Practice and Research, vol. 24, no. 2, pp. 193-201, 2010.

[77] N. Havu, "Enterochromaffin-like cell carcinoids of gastric mucosa in rats after life-long inhibition of gastric secretion," Digestion, vol. 35, no. 1, pp. 42-55, 1986.

[78] W. R. Garnett, "Considerations for long-term use of protonpump inhibitors," American Journal of Health-System Pharmacy, vol. 55, no. 21, pp. 2268-2279, 1998.

[79] J. W. Freston, "Long-term acid control and proton pump inhibitors: interactions and safety issues in perspective," American Journal of Gastroenterology, vol. 92, 4, pp. 515-575, 1997.

[80] J. W. Freston, P. A. Rose, C. A. Heller, M. Haber, and D. Jennings, "Safety profile of lansoprazole: the US clinical trial experience," Drug Safety, vol. 20, no. 2, pp. 195-205, 1999.

[81] B. Thjodleifsson, G. Rindi, R. Fiocca et al., "A randomized, double-blind trial of the efficacy and safety of 10 or $20 \mathrm{mg}$ rabeprazole compared with $20 \mathrm{mg}$ omeprazole in the maintenance of gastro-oesophageal reflux disease over 5 years," Alimentary Pharmacology and Therapeutics, vol. 17, no. 3, pp. 343-351, 2003.

[82] Y. X. Yang, J. D. Lewis, S. Epstein, and D. C. Metz, "Longterm proton pump inhibitor therapy and risk of hip fracture," Journal of the American Medical Association, vol. 296, no. 24, pp. 2947-2953, 2006.

[83] P. Vestergaard, L. Rejnmark, and L. Mosekilde, "Proton pump inhibitors, histamine $\mathrm{H} 2$ receptor antagonists, and other antacid medications and the risk of fracture," Calcified Tissue International, vol. 79, no. 2, pp. 76-83, 2006.

[84] L. E. Targownik, L. M. Lix, C. J. Metge, H. J. Prior, S. Leung, and W. D. Leslie, "Use of proton pump inhibitors and risk of osteoporosis-related fractures," Canadian Medical Association Journal, vol. 179, no. 4, pp. 319-326, 2008.

[85] S. L. Gray, A. Z. Lacroix, J. Larson et al., "Proton pump inhibitor use, hip fracture, and change in bone mineral density in postmenopausal women: results from the women's health initiative," Archives of Internal Medicine, vol. 170, no. 9, pp. 765-771, 2010.

[86] J. Leonard, J. K. Marshall, and P. Moayyedi, "Systematic review of the risk of enteric infection in patients taking acid suppression," American Journal of Gastroenterology, vol. 102, no. 9, pp. 2047-2056, 2007.

[87] N. Sultan, J. Nazareno, and J. Gregor, “Association between proton pump inhibitors and respiratory infections: a systematic review and meta-analysis of clinical trials," Canadian Journal of Gastroenterology, vol. 22, no. 9, pp. 761-766, 2008.

[88] L. Lombardo, M. Foti, O. Ruggia, and A. Chiecchio, "Increased incidence of small intestinal bacterial overgrowth during proton pump inhibitor therapy," Clinical Gastroenterology and Hepatology, vol. 8, no. 6, pp. 504-508, 2010.

[89] K. E. L. McColl, "Effect of proton pump inhibitors on vitamins and iron," American Journal of Gastroenterology, vol. 104, 2, pp. S5-S9, 2009.

[90] A. A. Alkhatib, F. A. Elkhatib, and O. F. Khatib, "Gastric acidreducing medications and clopidogrel: what are the latest FDA recommendations," American Journal of Gastroenterology, vol. 105, no. 5, p. 1211, 2010.

[91] R. Jones, H. R. Liker, and P. Ducrotté, "Relationship between symptoms, subjective well-being and medication use in gastro-oesophageal reflux disease," International Journal of Clinical Practice, vol. 61, no. 8, pp. 1301-1307, 2007.

[92] A. Lehmann, "Novel treatments of GERD: focus on the lower esophageal sphincter," European Review for Medical and Pharmacological Sciences, vol. 12, no. 1, pp. 103-110, 2008.
[93] G. Sachs, J. M. Shin, C. Briving, B. Wallmark, and S. Hersey, "The pharmacology of the gastric acid pump: the $\mathrm{H}^{+}, \mathrm{K}^{+}$ ATPase," Annual Review of Pharmacology and Toxicology, vol. 35, pp. 277-305, 1995.

[94] J. M. Shin, M. Besancon, K. Bamberg, and G. Sachs, "Structural aspects of the gastric H,K ATPase," Annals of the New York Academy of Sciences, vol. 834, pp. 65-76, 1997.

[95] J. Dent, P. J. Kahrilas, J. Hatlebakk et al., "A randomized, comparative trial of a potassium-competitive acid blocker (AZD0865) and esomeprazole for the treatment of patients with nonerosive reflux disease," American Journal of Gastroenterology, vol. 103, no. 1, pp. 20-26, 2008.

[96] P. J. Kahrilas, J. Dent, K. Lauritsen et al., "A randomized, comparative study of three doses of AZD0865 and esomeprazole for healing of reflux esophagitis," Clinical Gastroenterology and Hepatology, vol. 5, no. 12, pp. 13851391, 2007.

[97] Takeda Pharmaceutical company Ltd, Product pipeline Takeda Pharmaceutical company Ltd, 2009.

[98] Yuhan Corporation, R\&D Activity Pipeline, Yuhan Corporation, Yuhan Corporation, 2009.

[99] N. Vakil, "Review article: new pharmacological agents for the treatment of gastro-oesophageal reflux disease," Alimentary Pharmacology and Therapeutics, vol. 19, no. 10, pp. 10411049, 2004.

[100] Janssen Pharmaceutical, Letter. Propulsid tablets and suspension (cisapride), Janssen Pharmacetica. 2000.

[101] C. A. Thompson, "Novartis suspends tegaserod sales at FDA's request," American Journal of Health-System Pharmacy, vol. 64, no. 10, p. 1020, 2007.

[102] ARYZX Therapeutics Inc, 2009 Annual Report on Form 10K, ARYX Therapeutics Inc, 2008.

[103] NCT00539240: Role of pain modulation in GERD patients who failed standard dose PPI., 2009, http://www.clinicaltrials.gov/.

[104] S. E. Attwood and J. P. Galmiche, "A debate on the roles of antireflux surgery and long-term acid suppression in the management of gastroesophgeal reflux disease," Frontline Gastroenterology, vol. 2, no. 4, pp. 206-211, 2011.

[105] "Laparoscopic antireflux surgery vs esomeprazole treatment for chronic GERD the LOTUS randomized clinical trial," The Journal of the American Medical Association, vol. 305, no. 19, pp. 1969-1977, 2011.

[106] S. J. Spechler and R. K. Goyal, "The columnar-lined esophagus, intestinal metaplasia, and Norman Barrett," Gastroenterology, vol. 110, no. 2, pp. 614-621, 1996.

[107] J. Lagergren, R. Bergstom, A. Lindgen, and O. Nyren, "Symptomatic gastroesophgeal reflux as a risk factor for esophgeal adenocarcinoma," The New England Journal of Medicine, vol. 340, pp. 825-831, 1999.

[108] S. Rakita, D. Villadolid, A. Thomas et al., "Laparoscopic nissen fundoplication offers high patient satisfaction with relief of extraesophageal symptoms of gastroesophageal reflux disease," American Surgeon, vol. 72, no. 3, pp. 207-212, 2006.

[109] T. K. Meyer, E. Olsen, and A. Merati, "Contemporary diagnostic and management techniques for extraesophageal reflux disease," Current Opinion in Otolaryngology and Head and Neck Surgery, vol. 12, no. 6, pp. 519-524, 2004.

[110] D. R. Lindstrom, J. Wallace, T. A. Loehrl, A. L. Merati, and R. J. Toohill, "Nissen fundoplication surgery for extraesophageal manifestations of gastroesophageal reflux (EER)," Laryngoscope, vol. 112, no. 10, pp. 1762-1765, 2002.

[111] B. K. Oelschlager, T. R. Eubanks, D. Oleynikov, C. Pope, and C. A. Pellegrini, "Symptomatic and physiologic outcomes 
after operative treatment for extraesophageal reflux," Surgical Endoscopy and Other Interventional Techniques, vol. 16, no. 7, pp. 1032-1036, 2002.

[112] P. Yau, D. I. Watson, P. G. Devitt, P. A. Game, and G. G. Jamieson, "Laparoscopic antireflux surgery in the treatment of gastroesophageal reflux in patients with Barrett esophagus," Archives of Surgery, vol. 135, no. 7, pp. 801-805, 2000.

[113] M. Luostarinen, J. Isolauri, J. Laitinen et al., "Fate of Nissen fundoplication after 20 years. A clinical, endoscopical, and functional analysis," Gut, vol. 34, no. 8, pp. 1015-1020, 1993.

[114] J. Johansson, F. Johnsson, B. Joelsson, C. H. Floren, and B. Walther, "Outcome 5 years after $360^{\circ}$ fundoplication for gastro-oesophageal reflux disease," British Journal of Surgery, vol. 80, no. 1, pp. 46-49, 1993.

[115] M. Catarci, P. Gentileschi, C. Papi et al., "Evidence-based appraisal of antireflux fundoplication," Annals of Surgery, vol. 239, no. 3, pp. 325-337, 2004.

[116] L. Rydberg, M. Ruth, and L. Lundell, "Mechanism of action of antireflux procedures," British Journal of Surgery, vol. 86, no. 3, pp. 405-410, 1999.

[117] H. K. Jung, S. Halder, M. McNally et al., "Overlap of gastrooesophageal reflux disease and irritable bowel syndrome: prevalence and risk factors in the general population," Alimentary Pharmacology and Therapeutics, vol. 26, no. 3, pp. 453-461, 2007.

[118] D. R. De Vries, M. A. Van Herwaarden, A. Baron, A. J. P. M. Smout, and M. Samsom, "Concomitant functional dyspepsia and irritable bowel syndrome decrease healthrelated quality of life in gastroesophageal reflux disease," Scandinavian Journal of Gastroenterology, vol. 42, no. 8, pp. 951-956, 2007.

[119] V. Stanghellini, G. Barbara, R. Cogliandro et al., "Overlap between GERD and IBS: irrefutable but subtle," Journal of Clinical Gastroenterology, vol. 41, 2, pp. S114-S117, 2007.

[120] C. H. Knowles and Q. Aziz, "Visceral hypersensitivity in nonerosive reflux disease," Gut, vol. 57, no. 5, pp. 674-683, 2008.

[121] R. G. P. Watson, T. C. K. Tham, B. T. Johnston, and N. I. McDougall, "Double blind cross-over placebo controlled study of omeprazole in the treatment of patients with reflux symptoms and physiological levels of acid reflux-the 'sensitive oesophagus,"' Gut, vol. 40, no. 5, pp. 587-590, 1997.

[122] J. Zimmerman and T. Hershcovici, "Bowel symptoms in nonerosive gastroesophageal reflux disease: nature, prevalence, and relation to acid reflux," Journal of Clinical Gastroenterology, vol. 42, no. 3, pp. 261-265, 2008. 


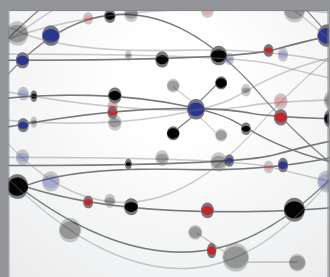

The Scientific World Journal
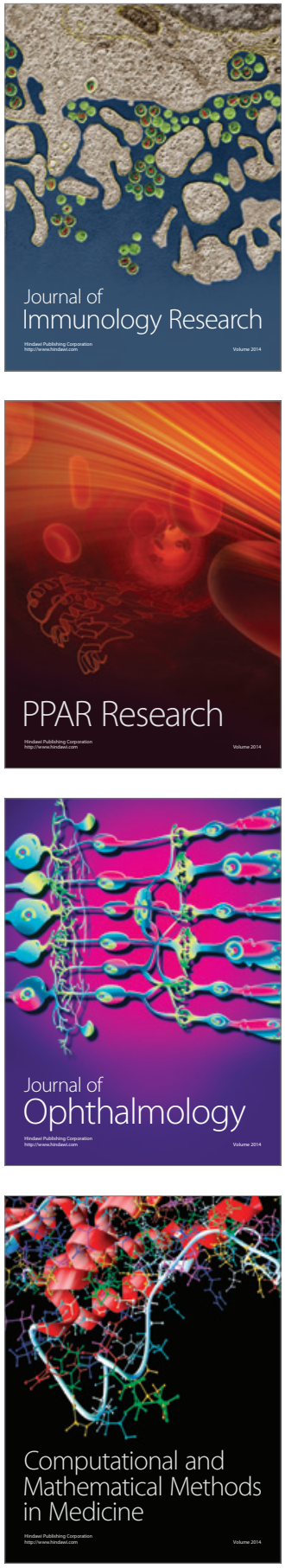

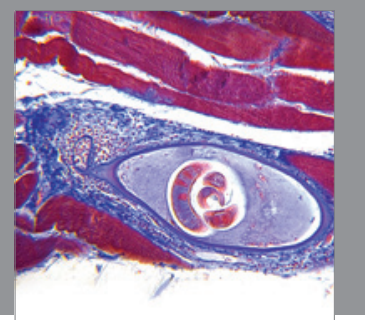

Gastroenterology

Research and Practice
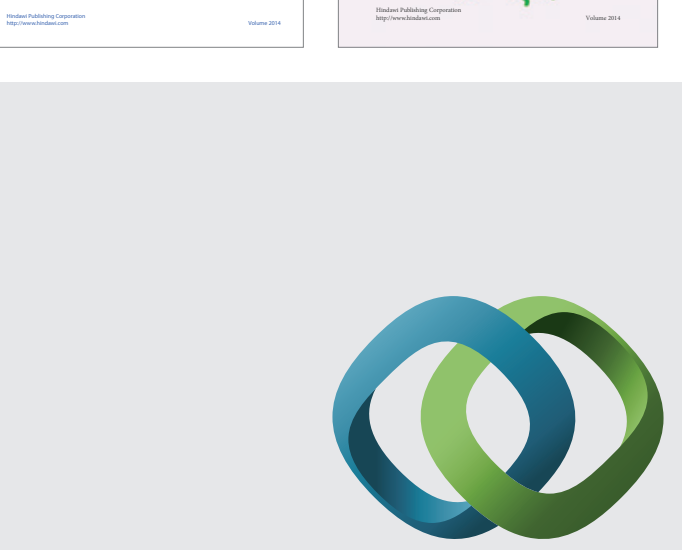

\section{Hindawi}

Submit your manuscripts at

http://www.hindawi.com
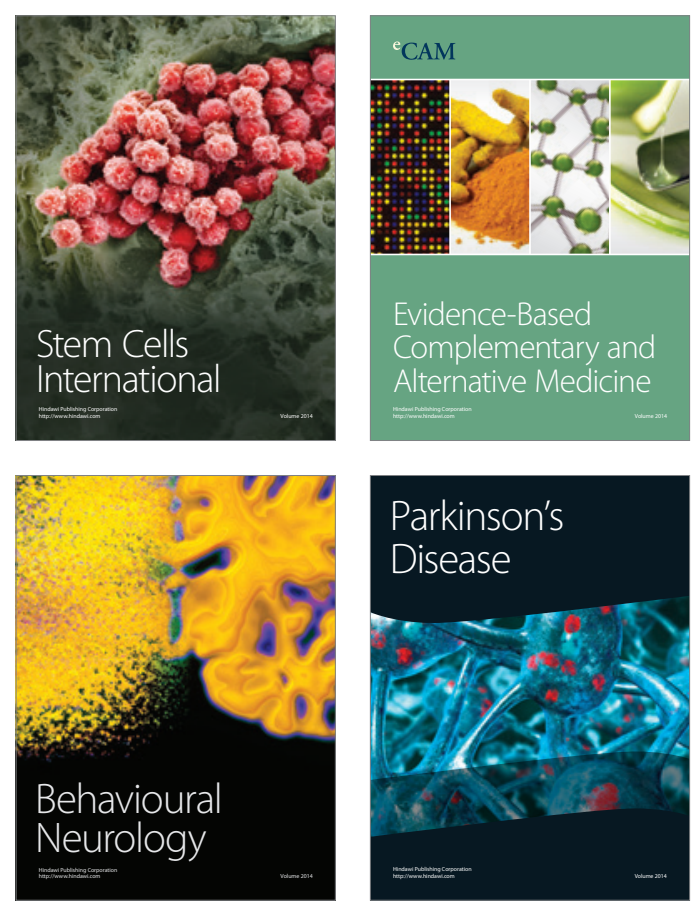

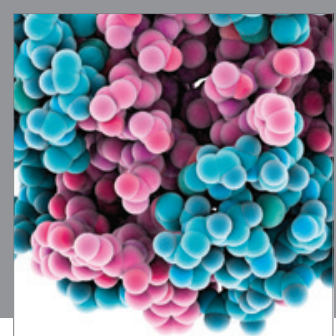

Journal of
Diabetes Research

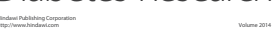

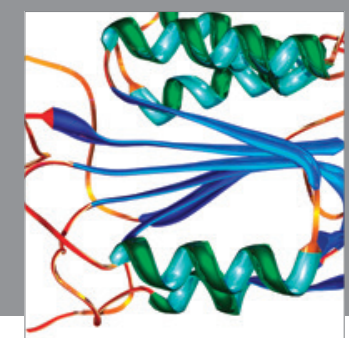

Disease Markers
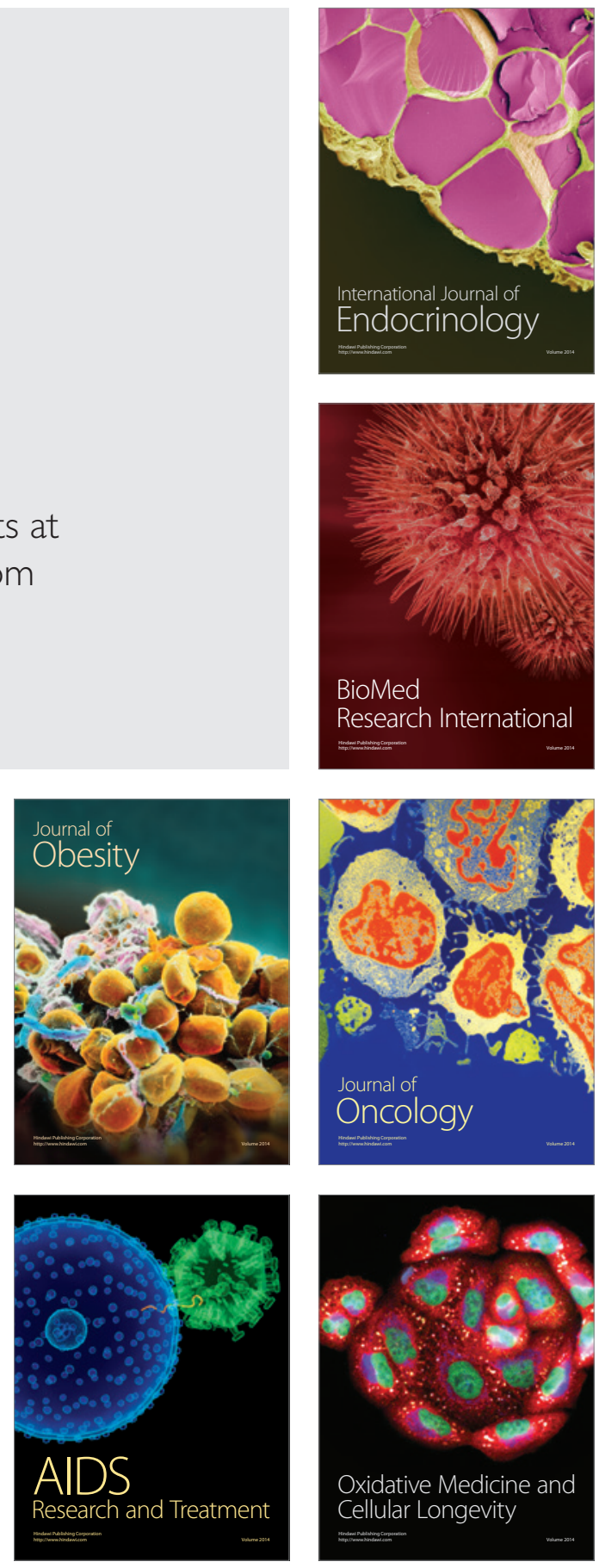